\title{
Predicted Properties of the Superheavy Elements. III. Element 115, Eka-Bismuth ${ }^{1 a}$
}

\author{
O. L. Keller, Jr.,* tb C. W. Nestor, Jr., \\ Oak Ridge National Laboratory, Oak Ridge, Tennessee 37830 \\ and Burkhard Fricke
}

Gesellschaft für Schwerionenforschung, Darmstadt, BRD, Germany (Received April 29, 1974)

Publication costs assisted by Oak Ridge National Laboratory

\begin{abstract}
Element 115 is expected to be in group V-a of the periodic table and have most stable oxidation states of I and III. The oxidation state of I, which plays a minor role in bismuth chemistry, should be a major factor in 115 chemistry. This change will arise because of the large relativistic splitting of the spherically symmetric $7 p_{1 / 2}$ shell from the $7 p_{3 / 2}$ shell. Element 115 will therefore have a single $7 p_{3 / 2}$ electron outside a $7 p^{2} 1 / 2$ closed shell. The magnitude of the first ionization energy and ionic radius suggest a chemistry similar to $\mathrm{Tl}^{+}$. Similar considerations suggest that $115^{3+}$ will have a chemistry similar to $\mathrm{Bi}^{3+}$. Hydrolysis will therefore be easy and relatively strongly complexing anions of strong acids will be needed in general to effect studies of complexation chemistry. Some other properties of 115 predicted are as follows: ionization potentials I $5.2 \mathrm{eV}$, II $18.1 \mathrm{eV}$, III $27.4 \mathrm{eV}$, IV $48.5 \mathrm{eV}, 0 \rightarrow 5^{+} 159 \mathrm{eV}$; heat of sublimation, $34 \mathrm{kcal}\left(\mathrm{g}\right.$-atom) ${ }^{-1}$; atomic radius, $2.0 \AA$; ionic radius, $115^{+} 1.5 \AA, 115^{3+} 1.0 \AA$; entropy, $16 \mathrm{cal} \mathrm{deg}^{-1}$ (g-atom) $)^{-1}\left(25^{\circ}\right)$; standard electrode potential $115^{+} \mid 115,-1.5 \mathrm{~V}$; melting and boiling points are similar to element 113 .
\end{abstract}

\section{Introduction}

Interest in superheavy elements remains high as new heavy-ion beams are being developed at the Super HILAC accelerator at Berkeley and construction proceeds on the UNILAC in Darmstadt. For over 1 year the Dubna heavyion accelerator group has been carrying out reactions that might produce superheavy elements. The recent Russian attempt to use the reaction of ${ }^{76} \mathrm{Ge}$ with ${ }^{232} \mathrm{Th}$ to reach elements in the island of stability was unfortunately unsuccessful. ${ }^{2}$ This suggests that the discovery of superheavy elements will probably be difficult, since the germanium plus thorium reaction was expected to be one of the more favorable cases. ${ }^{3}$ Chemical separations methods may now take on added importance in the search since they might offer much higher reliability and sensitivity than physical and nuclear methods. This was the case in the discovery of fission, for example. ${ }^{4}$

Element 115, eka-bismuth, is a particularly interesting case scientifically since its chemistry will be strongly altered by relativistic effects. ${ }^{5}$ There is, in fact, no element like 115 available to us in the present periodic system. An approach involving careful comparisons with the periodic table and analogies based on relativistic Hartree-Fock (rel HF) and relativistic Hartree-Fock-Slater (rel HFS) calculations appears to be best under these circumstances. Our predictions therefore involve first calculating electronic energy levels, ionization potentials, promotion energies to excited states, and atomic and ionic radii. The rel HFS programs were those of Oak Ridge and Fricke that we have used previously. 6,7 The relativistic Hartree-Fock program was very kindly made available to us by Desclaux. ${ }^{8}$

All three atomic calculational methods gave results which were close to each other. Further properties were estimated by combining the calculated quantities with valence bond theory or other general theories and by extrapolations in the periodic system. We first of all present in the following paragraphs our calculational results. These will then be combined in the following sections to arrive at specific predictions on the chemical properties of element 115 .

\section{Ionization Energies}

Calculated and experimental ionization energies of the Group V-a elements are given in Table I. The difference, $\Delta$, between the experimental and rel HFS results were used to estimate an "experimental" value for the ionization potentials of 115 and its ions. For comparison we give in Table II the rel HFS and experimental values for the ionization energies of the group III-a elements, $\mathrm{Pb}$, and $\mathrm{Po}$.

\section{Atomic and Ionic Radii}

In our considerations of chemical and physical properties the atomic and ionic radii are of considerable importance. Stabilization of an ion in a solution or crystal is dependent on the magnitude of decrease in the ionic radius with increase in its ionization (charge) since the radius strongly influences solvation and lattice energies. The atomic radii, on the other hand, are important for considerations involving valence bond theory. As pointed out by Pauling ${ }^{9}$ and by Drago, ${ }^{10}$ metallic atoms with a large volume have weaker covalent bonding because the valence electrons are spread over a larger space so that less overlap with the orbitals of anions results. Calculated atomic radii of the group $\mathrm{V}$-a elements along with their empirical values as given by Slater ${ }^{11}$ are given in Table III. Values for $\mathrm{Tl}, \mathrm{Pb}$, and $\mathrm{Po}$ are also given for comparison. The average radius of the outermost electronic shell, $\langle r\rangle$, was calculated both by the rel HF and rel HFS methods for $\mathrm{As}, \mathrm{Sb}, \mathrm{Bi}$, and 115. The results of the two methods are very similar. Also the radius of maximum radial charge density for the outermost shell, $r_{\max }$, is given. The latter is preferred by Slater ${ }^{11}$ for comparison with his empirical atomic radii. In Figure 1 we plot Slater's atomic radii and the calculated $r_{\text {max }}$ for the group V-a elements $v$. row of the periodic table. The reproduction of the trend of the empirical radii by the calculations is obviously excel- 
TABLE I: Ionization Energies of Group V-a Elements

\begin{tabular}{|c|c|c|c|c|c|}
\hline \multirow[b]{2}{*}{$Z$} & \multirow[b]{2}{*}{ Ion } & \multicolumn{4}{|c|}{ Ionization energies, eV } \\
\hline & & rel HF & rel HFS & Exptl & $\begin{array}{c}\Delta \text { (exptl } \\
- \text { rel } \\
\text { HFS })\end{array}$ \\
\hline \multirow[t]{4}{*}{15} & $\mathrm{P}$ & & 8.6 & 10.484 & 1.9 \\
\hline & $P^{+}$ & & 18.0 & 19.72 & 1.7 \\
\hline & $\mathrm{P}^{2+}$ & & 28.5 & 30.156 & 1.6 \\
\hline & $0 \rightarrow 5^{+}$ & & 169.8 & 176.72 & 6.9 \\
\hline \multirow[t]{5}{*}{33} & As & 8.44 & 8.00 & 9.81 & 1.8 \\
\hline & $\mathrm{As}^{+}$ & 17.0 & 17.1 & 18.63 & 1.6 \\
\hline & $\mathrm{As}^{2+}$ & 27.6 & 27.0 & 28.34 & 1.4 \\
\hline & $\mathrm{As}^{3+}$ & & 49.6 & 50.1 & 0.5 \\
\hline & $0 \rightarrow 5^{+}$ & 162.5 & 164.2 & 169.5 & 5.3 \\
\hline \multirow[t]{5}{*}{51} & $\mathrm{Sb}$ & 7.49 & 7.05 & 8.639 & 1.6 \\
\hline & $\mathrm{Sb}^{+}$ & 15.4 & 15.5 & 16.5 & 1.0 \\
\hline & $\mathrm{Sb}^{2+}$ & 24.6 & 24.1 & 25.3 & 1.2 \\
\hline & $\mathrm{Sb}^{3+}$ & & 43.6 & 44.1 & 0.5 \\
\hline & $0 \rightarrow 5^{+}$ & 142.4 & 144.6 & 150.5 & 5.9 \\
\hline \multirow[t]{5}{*}{83} & $\mathrm{Bi}$ & 6.58 & 6.09 & 7.287 & 1.2 \\
\hline & $\mathrm{Bi}^{+}$ & 15.5 & 15.7 & 16.68 & 0.94 \\
\hline & $\mathrm{Bi}^{2+}$ & 24.8 & 24.5 & 25.56 & 1.1 \\
\hline & $\mathrm{Bi}^{3+}$ & & 44.7 & 45.3 & 0.6 \\
\hline & $0 \rightarrow 5^{+}$ & 143.7 & 146.3 & 150.8 & 4.5 \\
\hline \multirow[t]{5}{*}{115} & 115 & 4.79 & 4.70 & $(5.2)$ & $(0.5)$ \\
\hline & $115^{+}$ & 17.70 & 17.4 & (18.1) & $(0.7)$ \\
\hline & $115^{2+}$ & 27.3 & 26.5 & $(27.4)$ & $(0.9)$ \\
\hline & $115^{3+}$ & & 48.0 & $(48.5)$ & $(0.5$ \\
\hline & $0 \rightarrow 5^{+}$ & 155 & 155 & (159) & (4) \\
\hline
\end{tabular}

TABLE II: Ionization Potentials of Group III-a, $\mathrm{Pb}$, and Po $(\mathrm{eV})$

\begin{tabular}{lccc}
\hline & rel HFS & Exptl & $\Delta$ \\
\hline $\mathrm{Ga}$ & 5.02 & 6.00 & 0.98 \\
& 20.21 & 20.51 & 0.30 \\
$0 \rightarrow 3^{+}$ & 30.50 & 30.70 & 0.20 \\
$\mathrm{In}$ & 55.73 & 57.21 & 1.48 \\
& 4.88 & 5.785 & 0.90 \\
& 18.41 & 18.86 & 0.45 \\
$0 \rightarrow 3^{+}$ & 27.56 & 28.03 & 0.47 \\
$\mathrm{Tl}$ & 50.85 & 52.67 & 1.82 \\
& 5.24 & 6.106 & 0.87 \\
$0 \rightarrow 3^{+}$ & 19.90 & 20.42 & 0.52 \\
$\mathrm{113}$ & 29.30 & 29.8 & 0.5 \\
& 54.4 & 56.3 & 1.90 \\
& 6.51 & $(7.4)$ & $(0.9)$ \\
$0 \rightarrow 3$ & 22.78 & $(23.3)$ & $(0.5)$ \\
$\mathrm{Pb}$ & 32.47 & $(33.0)$ & $(0.5)$ \\
& 61.76 & $(63.7)$ & $(1.9)$ \\
& 6.4 & 7.415 & 1.0 \\
$\mathrm{Po}$ & 14.0 & 15.028 & 1.0 \\
& 31.6 & 31.93 & 0.3 \\
& 7.2 & 8.43 & 1.2 \\
& 14.8 & & \\
& 26.8 & &
\end{tabular}

TABLE III: Slater Atomic Radius

\begin{tabular}{rlcccc}
\hline & & & \multicolumn{2}{c}{ Atomic radius } & \\
\cline { 4 - 5 }$Z$ & Element & rel HF, $\langle r\rangle$ & $\begin{array}{c}\text { rel HFS, } \\
\langle\boldsymbol{r}\rangle\end{array}$ & $\begin{array}{c}\text { rel HFS, } \\
\left(r_{\max }\right)\end{array}$ & $\begin{array}{c}\text { Slater } \\
\text { atomic } \\
\text { radius }\end{array}$ \\
\hline 15 & $\mathrm{P}$ & & 1.21 & 0.98 & 1.00 \\
33 & $\mathrm{As}$ & 1.35 & 1.31 & 1.07 & 1.15 \\
51 & $\mathrm{Sb}$ & 1.57 & 1.52 & 1.27 & $\mathbf{1 . 4 5}$ \\
83 & $\mathrm{Bi}$ & 1.72 & 1.67 & 1.41 & 1.60 \\
115 & eka-Bi & 2.07 & 2.00 & 1.77 & $(2.0)$ \\
81 & $\mathrm{Tl}$ & & 1.80 & 1.42 & 1.90 \\
82 & $\mathrm{~Pb}$ & & 1.58 & 1.22 & 1.80 \\
84 & Po & & 1.52 & 1.21 & 1.90
\end{tabular}

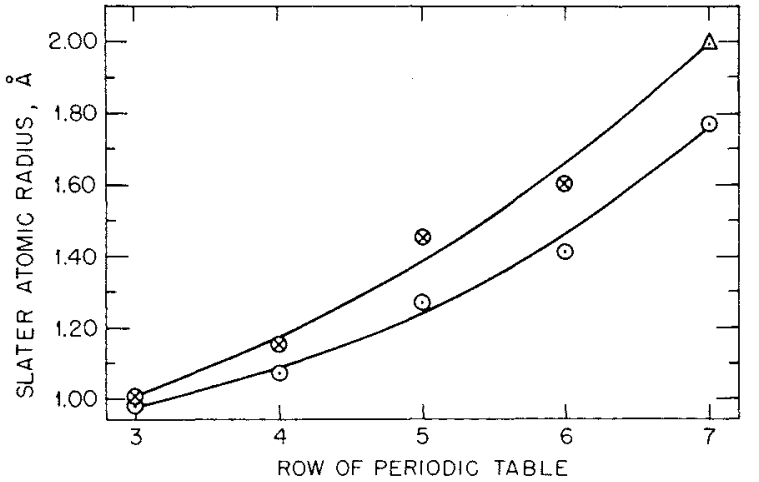

Figure 1. Slater atomic radii of group $V$-a elements $(\theta)$, extrapolated atomic radius of element $115(\Delta)$ and maximum radial charge density in the outermost shell computed by rel HFS.

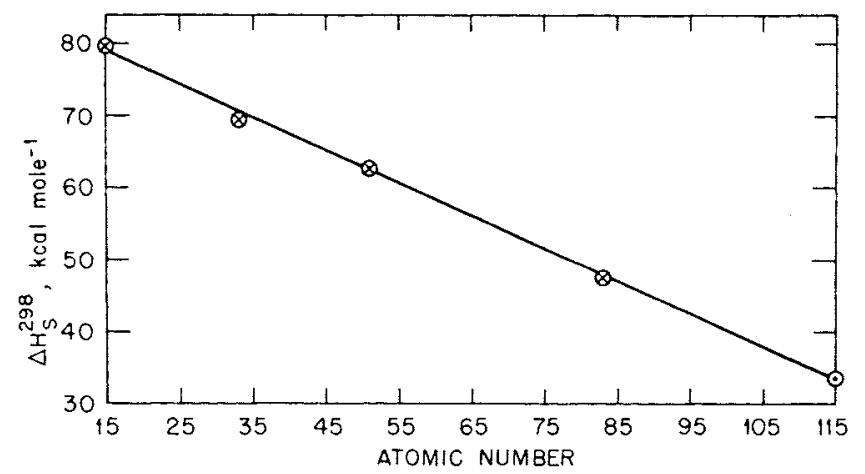

Figure 2. Heat sublimation of element 115.

lent, so we can use the plot of $r_{\max }$ with confidence as a guide in extrapolating to the value of $2.0 \AA$ for the atomic radius of 115 . This value is the same as our calculated values of $\langle r\rangle$.

In Table IV the computed values of $\langle r\rangle$ and $r_{\max }$ are given for the +1 and +2 or +3 ions of thallium, lead, bismuth, polonium, 113, and 115. Empirical ionic radii from Shannon and Prewitt ${ }^{12}$ are given in the last column for the known ions. By comparison of the calculated radii with the elements whose radii are known, we estimate the radii of $\mathrm{Bi}^{+}, \mathrm{Po}^{2+}, 113^{+}, 113^{3+}, 115^{+}$, and $115^{3+}$. The ionic radius of $115^{+}$as derived in this way $(1.5 \AA)$ is found to be close to that of $\mathrm{Tl}^{+}$and $\mathrm{Bi}^{+}$. The ionic radius of $115^{3+}(1.0 \AA)$ is found to be close to that of $\mathrm{Bi}^{3+}$, but somewhat larger than $\mathrm{Tl}^{3+}$.

\section{Heat of Sublimation}

The heat of sublimation, $\Delta H_{\mathrm{s}}{ }^{298}$, was obtained by extrapolation of the values ${ }^{13}$ for $\mathrm{P}, \mathrm{As}, \mathrm{Sb}$, and $\mathrm{Bi}$ vs. atomic number, $Z$. As shown in Figure $2, \Delta H_{\mathrm{s}}{ }^{298}$ for 115 is $34 \mathrm{kcal}$ (gatom) ${ }^{-1}$. David ${ }^{14}$ extrapolated $\log \Delta H_{\mathrm{s}}{ }^{298}$ vs. $\log Z$ to obtain $35 \mathrm{kcal}$ (g-atom) ${ }^{-1}$. These simple extrapolations $\mathrm{s}^{6,14}$ also yield $34 \mathrm{kcal}$ (g-atom) $)^{-1}$ for the $\Delta H_{\mathrm{s}}{ }^{298}$ of element 113 . Since 115 and 113 are close together in the periodic system and both have a single $7 p$ electron outside of closed shells, it is not surprising that their heats of sublimation would be similar. The higher first ionization potential of element 113 (Tables I and II) and its possibly smaller atomic radius might indicate that it would have a higher heat of sublimation than 115 . The results obtained by extrapolation indicate a higher polarizability of 115 than 113 to counteract 
TABLE IV: Radii of Ions of $\mathrm{Tl}, \mathrm{Pb}, \mathrm{Bi}$, Po, 113, and $115(\AA)$

\begin{tabular}{|c|c|c|c|c|}
\hline \multirow[b]{2}{*}{$Z$} & \multirow[b]{2}{*}{ Ion } & \multicolumn{2}{|c|}{ rel HFS (calcd) } & \multirow{2}{*}{$\begin{array}{l}\text { Ionic } \\
\text { radius }^{a}\end{array}$} \\
\hline & & $\langle r\rangle$ & $r_{\max }$ & \\
\hline \multirow[t]{2}{*}{81} & $\mathrm{Tl}+$ & 1.23 & 1.11 & 1.50 \\
\hline & $\mathrm{Tl}^{3+}$ & 0.69 & 0.60 & 0.88 \\
\hline \multirow[t]{2}{*}{82} & $\mathbf{P b}^{+}$ & 1.43 & 1.18 & \\
\hline & $\mathbf{P b}^{2+}$ & 1.12 & 0.99 & 1.18 \\
\hline \multirow[t]{2}{*}{83} & $\mathrm{Bi}^{+}$ & 1.33 & 1.19 & $(1.5)$ \\
\hline & $\mathrm{Bi}^{3+}$ & 1.04 & 0.97 & 1.02 \\
\hline \multirow[t]{2}{*}{84} & $\mathrm{Po}^{+}$ & 1.41 & 1.18 & \\
\hline & $\mathrm{Po}^{2+}$ & 1.18 & 1.03 & $(1.2)$ \\
\hline \multirow[t]{2}{*}{113} & $113^{+}$ & 1.16 & 1.05 & $(1.4)$ \\
\hline & $113^{3+}$ & 0.82 & 0.72 & $(1.0)$ \\
\hline \multirow[t]{2}{*}{115} & $115^{+}$ & 1.25 & 1.12 & $(1.5)$ \\
\hline & $115^{3+}$ & 1.01 & 0.95 & $(1.0)$ \\
\hline
\end{tabular}

a Estimated values in parentheses. Empirical values from ref 12 .

the ionization energy and possible radius differences. The rather high promotion energy of $7.4 \mathrm{eV}$ from the $7 \mathrm{~s}^{2} 7 \mathrm{p}$ ground state of element 113 to the $7 \mathrm{~s} 7 \mathrm{p}^{2}$ trigonally hybridized valence state is an indication of a low polarizability compared to element 115 whose promotion energy from the $7 p^{2}{ }_{1 / 2} 7 p_{3 / 2}$ state to the $7 p_{1 / 2} 7 p^{2} 3 / 2$ state is calculated to be $4.8 \mathrm{eV}$ (Table $\mathrm{V}$ where 115 is included under group III-a for tabular convenience).

The melting point and boiling point of 115 can be expected to be close to the values for 113 given in paper I of this series. ${ }^{6}$

\section{Excited State Energies}

For $115(\mathrm{~V})$ the promotion energy to the trigonal-bipyramidal $\mathrm{sp}^{3} \mathrm{~d}$ valence state is needed. The promotion energies for the group $\mathrm{V}$-a elements from the $\mathrm{s}^{2} \mathrm{p}^{3}$ ground state to the $\mathrm{sp}^{3} \mathrm{~d}$ valence state are therefore also given in Table $\mathrm{V}$. The rather high promotion energy for $115(\mathrm{~V})$ of $18.4 \mathrm{eV}$ compared to the value for $\mathrm{Bi}(\mathrm{V})$ of $15.5 \mathrm{eV}$ indicates that the group valence will be even less important for eka-bismuth than for bismuth.

\section{The Nature of the $115^{+}$Ion}

We expect that the chemistry of $115^{+}$will be found more analogous to $\mathrm{Tl}^{+}$than any other ion in the periodic system. This prediction is based on the values we have obtained for its ionization energy, ionic radius, and polarizability. The background for these conclusions follows.

The ground-state electronic configuration of element 115 is $7 s^{2} 1 / 27 p^{2}{ }_{1 / 2} 7 p_{3 / 2}$. The presence of the $7 p^{2}{ }_{1 / 2} 7 p_{3 / 2}$ groundstate configuration of 115 invites comparison to the $s^{2} p$ ground state of the group III-a elements. This is true because the $7 p_{1 / 2}$ orbital is spherically symmetric (Figure 3 ) in the relativistic limit and is therefore rather like an $\mathrm{s}$ orbital. Most particularly, the $7 \mathrm{p}^{2}{ }_{1 / 2}$ shell is closed analogous to an $s^{2}$ closed shell. Thus the $7 p_{3 / 2}$ electron is the first electron added outside closed shells and as a result its ionization energy is rather low $(5.2 \mathrm{eV})$. The situation with respect to ionization energy is found to be similar to Tl which has a $6 p_{1 / 2}$ electron outside of closed shells and has a first ionization energy of $6.1 \mathrm{eV}$.

A second important determining factor in the chemistry of $115^{+}$will be its ionic radius compared to its atomic radius. A large decrease in radius indicates stabilization for the oxidation state involved. This stabilization is due to the accompanying increase in solvation or lattice energy. The decrease in radius on ionizing the $7 p_{3 / 2}$ electron to form $115^{+}$
TABLE V: Promotion Energies ${ }^{a}$

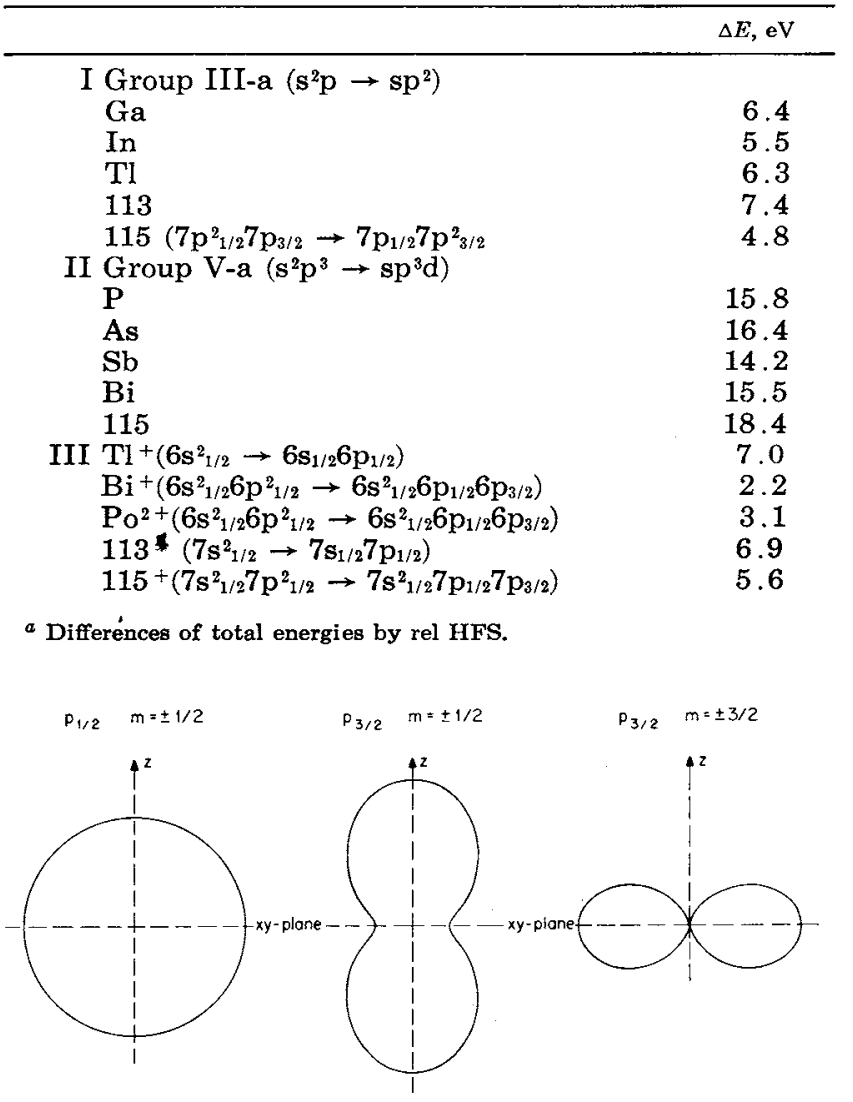

Figure 3. Angular distributions of relativistic p orbitals.

with a $7 \mathbf{p}^{2}{ }_{1 / 2}$ outer shell is $0.5 \AA$, quite comparable to the change of $0.4 \AA$ in going from $\mathrm{Tl}$ to $\mathrm{Tl}^{+}$. In the case of $\mathrm{Bi}^{+}$ the decrease is only about $0.1 \AA$. This small decrease in radius coupled with the higher first ionization energy of 7.3 $\mathrm{eV}$ explains why $\mathrm{Bi}^{+}$is not found in aqueous solutions (although it is found in molten salt media $\left.{ }^{16}\right) . \mathrm{Tl}^{+}$is, of course, stable in aqueous solutions. At bismuth the relativistic effects have not become large enough to allow the two electrons in the $6 \mathrm{p}_{1 / 2}$ orbital to form a strongly closed shell. For this reason, $115^{+}$is found to be more analogous to $\mathrm{Tl}^{+}$than to $\mathrm{Bi}^{+}$in its ionization potential and ionic radius.

There is, however, a further question about $115^{+}$, and this concerns how strong a " $b$ " metal character it will have. ${ }^{15} \mathrm{Tl}^{+}$is intermediate in its behavior between $\mathrm{Cu}^{+}$, $\mathrm{Ag}^{+}$, and $\mathrm{Au}^{+}$and the alkali metals. ${ }^{17}$ In analogy to the "b" cations, $\mathrm{Tl}^{+}$forms an insoluble chloride, bromide, iodide, sulfate, and sulfide. On the other hand, $\mathrm{Tl}^{+}$resembles the alkali metals in forming a soluble cyanide, hydroxide, carbonate, and oxalate. In contrast to $\mathrm{Cu}^{+}, \mathrm{Ag}^{+}$, and $\mathrm{Au}^{+}, \mathrm{Tl}^{+}$ forms only weak complexes with anions such as $\mathrm{Cl}^{-}, \mathrm{Br}^{-}$, and $\mathrm{I}^{-}$. It is for this reason, for example, that $\mathrm{TICl}$ is not made more soluble ${ }^{18}$ by excess $\mathrm{HCl}$ whereas $\mathrm{AgCl}$ dissolves.

Dunitz and Orgel ${ }^{19}$ found a rough correlation between $d-s$ separation energies and the tendency of $d^{10}$ ions to distort or to show covalency effects in their bonding. The $\mathrm{d}-\mathrm{s}$ separation energies for the " $b$ " type ions $\mathrm{Cu}^{+}, \mathrm{Ag}^{+}$, and $\mathrm{Au}^{+}$are $2.7,4.8$, and $1.9 \mathrm{eV}$, respectively. ${ }^{7}$ Of course, their radii would be expected to have an importance as well. The Slater atomic radii ${ }^{11}$ are $\mathrm{Cu}(1.35 \AA), \mathrm{Ag}(1.60 \AA)$, and $\mathrm{Au}$ $(1.35 \AA)$. The energies of separation in $\mathrm{Tl}^{+}, \mathrm{Bi}^{+}$, and $115^{+}$ between the ground and first excited states are given in 
TABLE VI: Standard Electrode Potential for the $115+115$ Couple ${ }^{a, b}$

\begin{tabular}{|c|c|c|c|c|c|c|}
\hline$\Delta H_{\mathrm{s}}^{298}$ & Ionization energy & $\Delta H_{\mathrm{hyd}}\left(115^{+}(\mathrm{aq})\right)$ & $\bar{S}_{116+(a q)}$ & $\bar{S}^{\circ}{ }_{118(g)}$ & $-T \Delta S$ & $E^{\circ}$ \\
\hline 1.5 & 5.2 & -3.22 & $13.4 \times 10^{-4}$ & $6.9 \times 10^{-4}$ & +0.4 & -1.5 \\
\hline
\end{tabular}

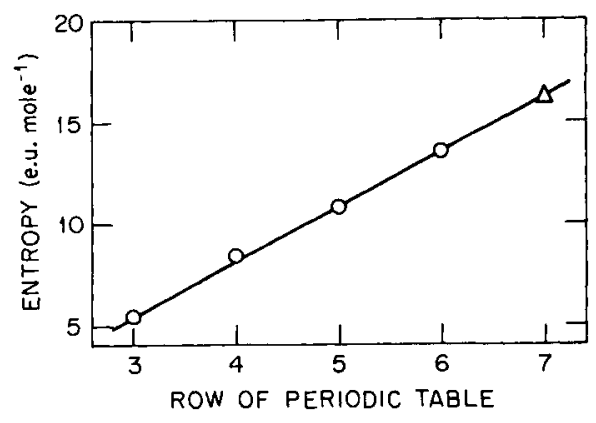

Figure 4. Entropy of elemental $115\left(298^{\circ} \mathrm{K}\right)$.

Table $\mathrm{V}$ (where the values of $\mathrm{Po}^{2+}$ and $113^{+}$are also given for comparison). The calculated energies are $\mathrm{Tl}^{+}(7.0 \mathrm{eV})$, $\mathrm{Bi}^{+}(2.2 \mathrm{eV})$, and $115^{+}(5.6 \mathrm{eV}) .115^{+}$is thus seen to be intermediate between $\mathrm{Tl}^{+}$and $\mathrm{Ag}^{+}$in its promotion energy, but the much larger atomic radius of $115(2.0 \AA)$ will weaken covalent bonding effects in $115^{+}$as it does in $\mathrm{Tl}^{+}$(atomic radius $=1.90 \AA$ ).

Also the large ionic radius of $115^{+}$of $1.5 \AA$ (Table IV) is similar to that of $\mathrm{Tl}^{+}(1.5 \AA)$, so the polarizing power of $115^{+}$on anions is expected to be weak as well.

The conclusion we reach then is that the ionic picture of bonding is applicable to $115^{+}$to a degree that is similar to that found for $\mathrm{Tl}^{+}$.

Smith and Davis ${ }^{20}$ have already pointed out expected relationships between $\mathrm{Bi}^{+}$and $115^{+}$with emphasis on spectroscopic and polycationic features.

\section{Standard Electrode Potential of the $115+\mid 115$ Couple}

For the cations of an ionic nature it is found that a calculation based on the Born-Haber cycle yields a reasonably quantitative value for the standard electrode potential. ${ }^{17} \mathrm{In}$ paper I of this series, ${ }^{6}$ it was found that the Born-Haber cycle approach plus the inclusion of the entropy term gave quantitative agreement for the $\mathrm{Tl}^{+} \mid \mathrm{Tl}$ couple. We therefore expect a similar calculation to be helpful in interpreting the chemistry of $115^{+}$.

Electrode potentials are usually related to the standard $\mathrm{H}^{+}(\mathrm{aq}) \mid 1 / 2 \mathrm{H}_{2}$ (g) couple whose potential is set equal to zero. We therefore consider the change in state for reduction of the aqueous metallic cation, $115^{+}(\mathrm{aq})$, to the metal, 115(s)

$$
115^{+}(\mathrm{aq})+(1 / 2) \mathrm{H}_{2}(\mathrm{~g}) \longrightarrow 115(\mathrm{~s})+\mathrm{H}^{+}(\mathrm{aq})
$$

The change in Gibbs free energy for this one electron reaction is related to the reduction potential and to the enthalpy and entropy by the equation

$$
\Delta G=-E^{\circ}=\Delta H-T \Delta S \text { (units in eV) }
$$

The enthalpy change can be obtained using the BornHaber cycle. ${ }^{6}$ The entropy change requires obtaining the elemental entropy of 115 metal by extrapolation as shown in Figure 4. The entropy of the aqueous metal ion can be calculated using the equation of Powell and Latimer. ${ }^{6,21}$ The results are given in Table VI. The $115^{+} \mid 115$ couple is found to have the standard electrode potential $-1.5 \mathrm{~V}$ com- pared to the $\mathrm{Tl}^{+} \mid \mathrm{Tl}$ couple of $-0.34 \mathrm{~V}$ and the $113^{+} \mid 113$ couple of $+0.6 \mathrm{~V}$. (Please note that in paper I the so-called "american convention" on sign was used so that the couple referred to an oxidation potential.)

\section{The Chemistry of the $115^{+}$Ion}

The $115^{+}$ion emerges as being more like the $\mathrm{Tl}^{+}$ion than any other species. It may even be still more ionic in its nature since the $115^{+} \mid 115$ couple is calculated to be more negative, although this calculation cannot be taken too literally. Nonetheless, as for $\mathrm{Tl}^{+}$, the complexing ability of $115^{+}$can be expected to be low with such anions as the halides, cyanide, and ammonia. Hydrolysis should not be a problem for 115 in the oxidation state of $I$, and the hydroxide, carbonate, oxalate, and fluoride should be soluble. The sulfide should be insoluble and the chloride, bromide, iodide, and thiocyanate only slightly soluble. Excess $\mathrm{HCl}$ will not affect the solubility of (115) Cl appreciably, for example. $115^{+}$should be more similar to $\mathrm{TI}^{+}$in this respect than to $\mathrm{Ag}^{+}$.

\section{The Chemistry of $115^{3+}$}

The other possible oxidation state of element 115 is +3 . We have not found it possible to predict the relative stabilities of the +1 and +3 states. In fact, their relative stabilities may well depend strongly on the state of complexation or hydrolytic conditions. As one might expect from simple extrapolation in the periodic table, we shall find that $115^{3+}$ is analogous to $\mathrm{Bi}^{3+}$.

The sum of the first three ionization energies of $\mathrm{Bi}$ is $49.53 \mathrm{eV}$, of $\mathrm{Tl}^{3+} 56.3 \mathrm{eV}$, and of $115^{3+}(51 \mathrm{eV})$ (Table I). The ionization energy of $115^{3+}$ is therefore close to $\mathrm{Bi}^{3+}$, but quite a bit below $\mathrm{Tl}^{3+}$. Furthermore, the ionic radius of $115^{3+}$ is found to be close to that of $\mathrm{Bi}^{3+}(1.0 \AA)$ but somewhat larger than that of $\mathrm{TI}^{3+}(0.88 \AA)$ (Table IV). On this basis $115^{3+}$ would be predicted to be more similar to $\mathrm{Bi}^{3+}$ than to $\mathrm{Tl}^{3+}$. However the differences between the chemistry of $\mathrm{Bi}^{3+}$ and $\mathrm{Tl}^{3+}$ are more of degree than of kind, $\mathrm{Bi}^{3+}$ being a relatively weak " $b$ " cation whereas $\mathrm{Tl}^{3+}$ is "super b."

In the first aqueous chemical studies of $115^{3+}$ hydrolysis should be avoided in order to obtain the more regular behavior usually associated with complex ion chemistry. In this connection, it should be remembered that mostly only the anions of strong acids are able to compete with hydrolysis in $\mathrm{Bi}^{3+}$ and $\mathrm{Tl}^{3+}$ aqueous chemistry. In their studies, Graner and Sillen $^{22}$ found that $0.05 M \mathrm{Bi}^{3+}$ hydrolyzes below an acidity of $0.5 M$ in $3 M$ perchlorate. Ahrland and Grenthe $^{23}$ worked at an acidity of $1 M$ in their studies of the chloride, bromide, and iodide complexes of bismuth. They still found $\mathrm{BiOCl}$ and $\mathrm{BiOBr}$ precipitating in the absence of extra halide. $\mathrm{Tl}^{3+}$ behaves similarly except that its complexation powers are stronger. Ahrland and Johansson $^{24}$ studied the chloride and bromide complexes of $\mathrm{Tl}^{3+}$ at an acidity of $3 M$. Woods, Gallagher, Hugus and King ${ }^{25}$ worked at an acidity of 0.5 and $3 M$ in their determinations of the association of $\mathrm{Cl}^{-}$with $\mathrm{Tl}^{3+}$. A helpful study has been done on this whole question by Biedermann and 
Spiro. ${ }^{26}$ These various studies suggest that the first ionexchange or solvent-extraction studies of $115^{3+}$ should be tried at a concentration of around $3 \mathrm{M}$ of a complexing acid such as $\mathrm{HCl}$ and/or a suitably high concentration of a relatively strongly complexing anion such as $\mathrm{Cl}^{-}$.

In the general chemistry of $115^{3+}$ we expect a behavior similar to $\mathrm{Bi}^{3+}$. The trichloride, tribromide, and triiodide of $115^{3+}$ will probably be soluble, and they may show a tendency to hydrolyze to form salts analogous to $\mathrm{BiOCl}$ and $\mathrm{BiOBr}$. The trifluoride should be insoluble like $\mathrm{BiF}_{3}$. Bismuth shows slight amphoteric character and thallium shows essentially none; so $115^{3+}$ is not expected to be amphoteric to any degree. Like $\mathrm{Tl}_{2} \mathrm{~S}_{3}$ and $\mathrm{Bi}_{2} \mathrm{~S}_{3},(115)_{2} \mathrm{~S}_{3}$ will be insoluble. The sulfate and nitrate will be soluble in the respective acids and the phosphate will be insoluble.

Acknowledgment. We gratefully acknowledge the continued interest and encouragement furnished by Glenn $T$. Seaborg to all of us working in the field of superheavy elements. We are particularly indebted to G. Pedro Smith for most illuminating discussions.

\section{References and Notes}

(1) (a) Research sponsored by the U. S. Atomic Energy Commission under contract with the Union Carbide Corporation. (b) Address correspondence to this author at Oak Ridge National Laboratory, Oak Ridge, Tenn 37830 .

(2) Yu. Ts. Oganessian, "Synthesis of Superheavy Elements," Proceedings of International Conference on Nuclear Physics," Munich, Aug 27-Sept $1,1973$.
(3) W. J. Swiatecki and C. F. Tsang, Nuclear Chemistry Annual Report No. LBL-666, Lawrence Berkeley Laboratory, 1971.

(4) O. R. Frisch and John A. Wheeler, Phys. Today, 20(7), 43 (1967)

(5) B. Fricke and J. T. Waber, Actinides Rev., 1, 433 (1971)

(6) O. L. Keller, J. L. Burnett, T. A. Carlson, and C. W. Nestor, Jr., J. Phys. Chem. 74, 1127 (1970)

(7) O. L. Keller, Jr., C. W. Nestor, Jr., T. A. Carlson, and B. Fricke, J. Phys. Chem., 77, 1806 (1973).

(8) J. P. Desclaux, private communication

(9) L. Pauling, J. Phys. Chem., 58, 662 (1954).

(10) R. S. Drago, J. Phys. Chem., 62, 353 (1958)

(11) J. C. Slater, Quantum Theory of Molecules and Solids, Vol. 2 McGraw-Hill, New York, N. Y., 1965.

(12) R. D. Shannon and C. T. Prewitt, Acta Crystallogr., Sect. B, 25, 925 (1969).

(13) D. R. Stull and G. C. Sinke, "Thermodynamic Properties of the Elements," American Chemical Society, Washington, D. C., 1956.

(14) F. David, "Prediction of the Oxidation-Reduction Properties of the Superheavy Elements 8s, 7p and 6d," Institut de Physique Nucléaire, Division de Radiochimie, RC-71-06, 1 Oct 1971

(15) See S. Ahrland, J. Chatt, and N. R. Davies, Quart. Rev. Chem. Soc., 12. 265 (1958), for a discussion of the $a / b$ classification of cations. A related scheme, based on the terminology "hard" and "soft," is given by R. G. Pearson, J. Amer. Chem. Soc., 85, 3533 (1963).

(16) N. J. Bjerrum, H. L. Davis, and G. Pedro Smith, Inorg. Chem., 6, 1603 (1967).

(17) C. S. G. Phillips and R. J. P. Williams, "Inorganic Chemistry," Oxford University Press, London, 1966, 2 volumes.

(18) T. E. Alekseeva, N. F. Arkhipova, and V. A. Rabinovich, Russ. J. Inorg Chem., 17, 140 (1972).

(19) J. D. Dunitz and L. E. Orgel, Advan. Inorg. Radiochem., 2, 1 (1960).

(20) G. P. Smith and H. L. Davis, Inorg. Nucl. Chem. Lett. 9 , 991 (1973).

(21) R. E. Powell and W. M. Latimer, J. Chem. Phys., 19, 1139 (1951).

(22) F. Graner and L. G. Sillen, Acta Chem. Scand., 1, 631 (1947)

(23) S. Ahrland and I. Grenthe, Acta. Chem. Scand., 11, 1111 (1957).

(24) S. Ahrland and L. Johansson, Acta Chem. Scand., 18, 2125 (1964).

25) J. M. Woods, P. K. Gallagher, Z. Z. Hugus, Jr., and E. L. King, inorg. Chem., 3, 1313 (1964).

(26) G. Biedermann and T. G. Spiro, Chem. Scr., 1, 155 (1971). 